\title{
A Survey of Patients' Perceptions of Pill Appearance and Responses to Changes in Appearance for Four Chronic Disease Medications
}

\author{
Ameet Sarpatwari, J.D., Ph.D. ', Joshua J. Gagne, Pharm.D., Sc.D. ' , Zhigang Lu, M.D. ', \\ Eric G. Campbell, Ph.D. ${ }^{2}$, Wendy J. Carman, Ph.D., M.P.H ${ }^{3}$, Cheryl L. Enger, Ph.D., M.S. ${ }^{3}$, \\ Sarah K. Dutcher, Ph.D. ${ }^{4}$, Wenlei Jiang, Ph.D. ${ }^{4}$, and Aaron S. Kesselheim, M.D., J.D., M.P.H. ${ }^{7}$
}

'Program On Regulation, Therapeutics, And Law (PORTAL), Division of Pharmacoepidemiology and Pharmacoeconomics, Department of Medicine, Brigham and Women's Hospital and Harvard Medical School, Boston, MA, USA; ${ }^{2}$ Center for Bioethics and Humanities, University of Colorado, Denver, CO, USA; ${ }^{3}$, Epidemiology, Optum, Ann Arbor, MI, USA; ${ }^{4}$ Office of Research and Standards, Office of Generic Drugs, Center for Drug Evaluation and Research, Food and Drug Administration, Silver Spring, MD, USA.

BACKGROUND: Generic versions of a drug can vary in appearance, which can impact adherence.

OBJECTIVE: To assess the preferences, perceptions, and responses of patients who experienced a change in the appearance of a generic medication.

DESIGN: Cross-sectional survey of patients from a large commercial health plan.

PARTICIPANTS: Adults receiving generic versions of lisinopril, fluoxetine, lamotrigine, or simvastatin who experienced a change in the color or shape of their pills between March 2014 and November 2015.

MAIN MEASURES: Likert-scale responses to questions concerning perceptions of generic drug safety and effectiveness, reliance on and preferences for pill appearance, and responses to pill appearance changes. Multivariable logistic regression-modeled predictors of seeking advice and adjusting use following a pill appearance change.

KEY RESULTS: Of 814 respondents (response rate = $41 \%$ ), $72 \%$ relied on pill appearance to ensure they took the correct medication. A similar percentage wanted their pills to remain the same color (72\%), shape (71\%), and size (75\%) upon refill, but 58\% would not have paid a \$1 premium on a $\$ 5$ co-pay to ensure such consistency. Most respondents $(86 \%)$ wanted their pharmacists to notify them about pill appearance changes, but only $37 \%$ recalled such notification; $21 \%$ thought they received the wrong medication, and $8 \%$ adjusted medication use. Younger respondents (18-33 vs. 50-57 years) were more likely to seek advice (odds ratio $[\mathrm{OR}]=1.91$; 95\% confidence interval [CI], 1.02-3.59), and respondents with lower household income $(<\$ 30,000$ vs. $>\$ 100,000)$ were more likely to adjust medication use (OR $=3.40 ; 95 \%$ CI, 1.09-10.67).

CONCLUSIONS: Requiring uniform pill appearance may help increase adherence but presents challenges. Standardized pharmacy notification and education policies may be a more feasible short-term solution.

Electronic supplementary material The online version of this article (https://doi.org/10.1007/s11606-018-4791-1) contains supplementary material, which is available to authorized users.

Received June 1, 2018

Revised October 12, 2018

Accepted November 28, 2018

Published online January 10, 2019
KEY WORDS: pill appearance; medication adherence; chronic diseases; survey.

J Gen Intern Med 34(3):420-8

DOI: $10.1007 / \mathrm{s} 11606-018-4791-1$

() Society of General Internal Medicine 2019

The growth of the modern generic drug industry has been a public health success. Generic drugs currently account for $89 \%$ of dispensed prescription medications and have saved the US health care system over \$1.6 trillion over the past decade, ${ }^{1}$ primarily through drug product selection laws that authorize - and in certain states mandate — pharmacists to fill prescriptions for brand-name drugs with lower-cost generic equivalents. ${ }^{2}$ Initiation of treatment with generics has also been found to improve medication adherence ${ }^{3}$ and patient health outcomes. ${ }^{4,5}$

Under the Federal Food, Drug, and Cosmetic Act and Food and Drug Administration (FDA) regulations, generic drugs must have the same active ingredient, dosage form, and dosage strength in comparison to their brand-name counterparts, and must deliver the active ingredient to the intended site of action at approximately the same rate and extent ("bioequivalence"). A review of all FDA generic drug approvals between 1996 and 2007 found a less than $5 \%$ average difference in bioequivalence between generic and brand-name drugs. ${ }^{6}$ The comparable safety and effectiveness of generic and brand-name drugs have been further supported by several well-controlled observational studies $^{7-9}$ and prospective trials. ${ }^{10-13}$

Yet, generic drugs need not physically resemble their comparable brand-name versions in terms of pill shape, color, or markings. For example, a study of 11,513 patients initiating a generic cardiovascular medication after hospitalization for a myocardial infarction between 2006 and 2011 found that 3287 (29\%) experienced a change in pill shape or color within a year. ${ }^{14}$ In some cases, brand-name drug manufacturers can claim ownership over the physical attributes of a pill as a form of intellectual property. ${ }^{15}$ 
Emerging observational research has suggested that changes in pill appearance can have important implications for patients. In a study of 61,522 patients initiating an antiepileptic between 2002 and 2006, the odds of non-persistence was $27 \%$ higher (adjusted odds ratio [OR] $=1.27$; 95\% confidence interval [CI],1.04-1.55) among patients who had experienced a preceding pill color change. ${ }^{16}$ In the study of patients initiating a generic cardiovascular medication after hospitalization for a myocardial infarction, non-persistence was associated with a preceding change in pill color (adjusted OR = $1.34 ; 95 \% \mathrm{CI}, 1.12-1.59$ ) and shape (adjusted $\mathrm{OR}=1.66 ; 95 \%$ CI,1.43-1.94). ${ }^{14}$

We sought to survey patients to gain insight into how changes in pill appearance changes may affect adherence. To do so, we selected a random sample of patients who had recently experienced a change in the appearance of their chronic generic medication and assessed their perceptions of the appearance change as well as their reported responses.

\section{METHODS}

\section{Study Design, Population, and Recruitment}

We conducted a cross-sectional survey of commercially insured adult patients receiving generic versions of one of the following medications: the antihypertensive lisinopril, the antidepressant fluoxetine, the antiepileptic lamotrigine, or the cholesterol-lowering drug simvastatin. We selected these medications because they are indicated for the treatment of chronic conditions and would usually be taken long-term - a situation in which pill appearance would be most salient. The qualifying event for potential survey inclusion was a change in the color or shape of a patient's medication between March 2014 and November 2015 as identified in their insurance claims data. The day on which this change occurred was considered the index date. Eligible patients were required to have had at least nine months of continuous enrollment in the insurance plan prior to the index date (the "pre-index period"), during which time they had at least one prescription fill and no change in the appearance of their medication and at least one International Classification of Diseases (ICD)-9 code for the medication's indication (Appendix 1).

We selected a random sample of 500 eligible patients for each study drug. Selected patients received a personalized first-class mailing containing an invitation letter, a patient informed consent statement, a self-administered paper survey, a postage-paid return envelope, and a $\$ 5$ bill. The invitation letter offered patients the opportunity to complete the survey online or via paper. Up to two reminder mailings were sent to patients over a one-month interval. Patients who completed the survey received a $\$ 20$ cash honorarium and a thank you note. A survey invitee was considered a non-responder if a completed survey was not received by the end of the data collection period in June 2016.

\section{Data Sources and Collection}

Patients were identified from the Optum Research Database (ORD), an administrative claims database for a large US commercial health plan. The ORD contains demographic, inpatient and outpatient medical claims, and prescription data on over twelve million geographically diverse enrollees, representing approximately $4 \%$ of the commercially insured US population (Appendix 2). For each patient, we extracted information on patient demographics (age at index date, sex, geographic region of residence), health care utilization during the pre-index period (number of physicians and emergency room visits, hospitalizations, unique medications dispensed, unique three-digit ICD-9 diagnosis codes), and type of study drug (national drug code [NDC], dosage, formulation) received at pre-index and index dispensings.

To identify the appearance of dispensed study medications, we used First Data Bank's MedKnowledge, a repository of prices and clinical information on FDA-approved drugs. Images of pills were collected via NDCs, which were categorized with regard to color and shape.

The survey was administered using a thirty-three-question, closed-field instrument, which had been pilot tested with a convenience sample and designed to take no more than twenty minutes to complete (Appendix 3). Topics included perceptions of generic drug safety and effectiveness, reliance on and preferences for pill appearance, responses to pill appearance changes, and respondent demographics (e.g., race/ethnicity, education, and household income). Patients were asked whether generic drugs were as safe and effective and had the same active ingredients and side effects as their brand-name counterparts, whether they relied on pill appearance to make sure they were taking the correct medication, whether they preferred consistent pill appearance following a refill, and how much they were willing to pay to ensure pill appearance consistency. Patients were additionally questioned as to whether and how they desired to be notified about pill appearance changes. Finally, patients were asked whether their pharmacist notified them about the qualifying change in the appearance of their medication and if they took specific actions in response, including seeking advice or altering medication use. Reliance, preferences, and perceptions were assessed using Likert scales.

\section{Statistical Analyses}

The response rate to the survey was calculated using the American Association of Public Opinion Research's second standard definition. ${ }^{17}$ Responses to select survey questions were combined into dichotomous variables to describe broader categories of patient perceptions and actions. Similar to prior surveys, ${ }^{18,19}$ we constructed a generic drug skepticism index, with respondents defined as skeptics if they answered neutrally or negatively to whether they believed generic drugs were as safe or effective or whether generic drugs have the same active ingredients or side effects as their brand-name 
counterparts. Respondents were additionally classified with regard to whether they sought advice about their qualifying pill appearance change from their pharmacist, their physician, or the Internet, and whether they adjusted the use of their medication, including switching back to the prior pill, using the medication less frequently or stopping the medication altogether.

We evaluated associations of demographic variables with survey responses using Pearson's chi-square, $t$, and one-way analysis of variance testing. We compared responses of patients taking each of the four study drugs descriptively. Multivariable logistic regression modeling was used to examine predictors of generic skepticism as well as the acts of seeking advice and adjusting medication use following the pill appearance change. For assessment of predictors of generic skepticism, independent variables included number and days supply of pre-index dispensings, number of concomitant medications, Charlson comorbidity index, time between index date and survey mailing, sex, age group, educational background, and household income. For assessments of seeking advice and adjusting medication use, the previously described elements of generic skepticism were also included as covariates. The Partners HealthCare Institutional Review Board and the New England Independent Review Board approved this study. All analyses were performed using SAS v.9.4.

\section{RESULTS}

\section{Response Rate and Demographics}

A total of 8703 patients in the ORD met the study inclusion criteria. Of 2000 patients randomly invited to participate, 814 (response rate $=41 \%$, Appendix 4) completed the survey. Drug-specific participation rates were $44 \%$ for lisinopril $(n=$ $222)$ and simvastatin $(n=219)$ users, $38 \%$ for fluoxetine $(n=$ $192)$ users, and $36 \%$ for lamotrigine $(n=181)$ users.

Among respondents, 690 (85\%) were Caucasian, and 333 $(41 \%)$ had a college degree (Table 1). A majority (450 [55\%]) were female, with greater disparity observed among lisinopril $($ female $=80[36 \%])$, fluoxetine $($ female $=142[74 \%])$, and lamotrigine (female $=126[70 \%]$ ) respondents than among simvastatin (female $=102[47 \%]$ ) respondents. Lisinopril respondents had on average greater comorbidity (Charlson comorbidity index $[\mathrm{CCI}]>2=35[16 \%]$ ) than fluoxetine $(\mathrm{CCI}>2=7[4 \%])$, lamotrigine $(\mathrm{CCI}>2=7[4 \%])$, and simvastatin $(\mathrm{CCI}>2=18[8 \%])$ respondents.

Compared to respondents, non-respondents were slightly younger $(<40$ years $=316[27 \%]$ vs. $<40$ years $=167[20 \%])$, and fewer had a pre-index $(n=342[29 \%]$ vs. 350 [43\%]) or index ( $n=169$ [14\%] vs. 188 [23\%]) dispensing of a ninetyday supply of their medication (Appendix 5). Respondents and non-respondents were similar with regard to sex (female, $n=450[55 \%]$ vs. $n=637[54 \%])$ and CCI (>2 $=67(8 \%)$ vs. $70(6 \%))$, and to average number of physician visits $(n=7$ [standard deviaton $(\mathrm{SD})=6]$ vs. $7[\mathrm{SD}=6])$, concomitant medications $(n=7[\mathrm{SD}=5]$ vs. $7[\mathrm{SD}=5])$, and study drug dispensings received $(n=6[\mathrm{SD}=3]$ vs. $6[\mathrm{SD}=3])$ in the preindex period.

\section{Generic Skepticism}

While perceptions of generic drugs were generally favorable, some respondents harbored concerns (Appendix 6). Twelve percent did not believe generic drugs were probably or definitely as effective as their brand-name counterparts, and $8 \%$ did not believe generic drugs were probably or definitely as safe. Similarly, $16 \%$ of respondents did not believe that generic drugs probably or definitely had the same side effects as their brand-name versions, and $14 \%$ did not believe that generic drugs probably or definitely had the same active ingredients. Based on these data, $26 \%$ of the study population qualified as generic skeptics. Such skepticism was more prevalent among lamotrigine (34\%) respondents than fluoxetine (26\%), lisinopril (22\%), and simvastatin (24\%) respondents.

\section{Pill Appearance Preferences}

Almost three-fourths (72\%) of respondents usually or always relied on pill appearance to make sure they were taking the correct medication. Accordingly, a similar percentage of respondents wanted their pills to remain the same color (72\%), shape $(71 \%)$, and size $(75 \%)$ when refilling their medication (Fig. 1a). Preferences were comparable for fluoxetine $($ color $=77 \%$, shape $=77 \%$, size $=75 \%$ ), lamotrigine ( color $=73 \%$, shape $=76 \%$, size $=82 \%$ ), and simvastatin (color $=75 \%$, shape $=71 \%$, size $=77 \%$ ) respondents. By contrast, fewer lisinopril $($ color $=64 \%$, shape $=61 \%$, size $=68 \%)$ respondents expressed a desire for their refills to appear the same.

To avoid a change in pill appearance, $42 \%$ of respondents would have paid a $\$ 1$ premium on a $\$ 5$ co-pay (Fig. 1b). However, only $8 \%$ would have paid a $\$ 5$ premium on a $\$ 10$ co-pay, and just $2 \%$ would have paid a $\$ 10$ premium on a $\$ 15$ co-pay, responses that were similar for each study drug. When appearance changes occur, $86 \%$ of respondents reported that they would like to be notified by their pharmacy (Fig. 1c). Over one-fifth of each respondent cohort expressed a desire for this notification to occur verbally, in person or on the phone: lisinopril (29\%), fluoxetine (23\%), lamotrigine $(33 \%)$, and simvastatin (26\%) (data not shown).

\section{Experience with Pill Appearance Change}

When their pills changed appearance, 19\% of respondents recalled their pharmacist talking to them about the change, and $30 \%$ recalled their pharmacist placing a sticker on their pill bottle alerting them to the change (data not shown). Fewer respondents taking lamotrigine (talking $=13 \%$, sticker $=20 \%$ ) recalled either action than respondents taking lisinopril (talking $=28 \%$, sticker $=40 \%$ ), fluoxetine (talking $=14 \%$, sticker $=30 \%$ ), and simvastatin (talking $=18 \%$, sticker $=29 \%$ ). In 
Table 1 Respondent Demographics

\begin{tabular}{|c|c|c|c|c|c|c|c|c|c|c|}
\hline & \multicolumn{2}{|c|}{$\begin{array}{l}\text { Lisinopril } \\
(N=222)\end{array}$} & \multicolumn{2}{|c|}{$\begin{array}{l}\text { Fluoxetine } \\
(N=192)\end{array}$} & \multicolumn{2}{|c|}{$\begin{array}{l}\text { Lamotrigine } \\
(N=181)\end{array}$} & \multicolumn{2}{|c|}{$\begin{array}{l}\text { Simvastatin } \\
(N=219)\end{array}$} & \multicolumn{2}{|c|}{$\begin{array}{l}\text { Overall }(N= \\
814)\end{array}$} \\
\hline & $N$ & $\%$ & $N$ & $\%$ & $N$ & $\%$ & $N$ & $\%$ & $N$ & $\%$ \\
\hline \multicolumn{11}{|l|}{ Age group (years) on index date } \\
\hline $18-29$ & 0 & 0 & 29 & 15 & 44 & 24 & 2 & 1 & 75 & 9 \\
\hline $30-39$ & 11 & 5 & 31 & 16 & 47 & 26 & 3 & 1 & 92 & 11 \\
\hline $40-49$ & 40 & 18 & 51 & 27 & 45 & 25 & 33 & 15 & 169 & 21 \\
\hline $50-59$ & 92 & 41 & 53 & 28 & 27 & 15 & 93 & 43 & 265 & 33 \\
\hline $60-69$ & 67 & 30 & 27 & 14 & 18 & 10 & 82 & 37 & 194 & 24 \\
\hline $70+$ & 12 & 5 & 1 & 1 & 0 & 0 & 6 & 3 & 19 & 2 \\
\hline \multicolumn{11}{|l|}{ Sex } \\
\hline Male & 142 & 64 & 50 & 26 & 55 & 30 & 117 & 53 & 364 & 45 \\
\hline Female & 80 & 36 & 142 & 74 & 126 & 70 & 102 & 47 & 450 & 55 \\
\hline \multicolumn{11}{|l|}{ Region of residence } \\
\hline Northeast & 11 & 5 & 12 & 6 & 24 & 13 & 36 & 16 & 83 & 10 \\
\hline South & 135 & 61 & 68 & 35 & 72 & 40 & 97 & 44 & 372 & 46 \\
\hline Midwest & 52 & 23 & 76 & 40 & 40 & 22 & 69 & 32 & 237 & 29 \\
\hline West & 24 & 11 & 36 & 19 & 45 & 25 & 17 & 8 & 122 & 15 \\
\hline \multicolumn{11}{|l|}{ Race/ethnicity } \\
\hline White/Caucasian & 182 & 82 & 176 & 92 & 153 & 85 & 179 & 82 & 690 & 85 \\
\hline Black/African-American & 13 & 6 & 0 & 0 & 1 & 1 & 11 & 5 & 25 & 3 \\
\hline Hispanic/Latino & 9 & 4 & 6 & 3 & 13 & 7 & 10 & 5 & 38 & 5 \\
\hline Asian/Pacific Islander & 5 & 2 & 1 & 1 & 4 & 2 & 4 & 2 & 14 & 2 \\
\hline American Indian/Native American & 1 & 1 & 1 & 1 & 0 & 0 & 2 & 1 & 4 & 1 \\
\hline Other & 4 & 2 & 2 & 1 & 5 & 3 & 6 & 3 & 17 & 2 \\
\hline Prefer not to answer & 8 & 4 & 6 & 3 & 5 & 3 & 7 & 3 & 26 & 3 \\
\hline \multicolumn{11}{|l|}{ Level of education } \\
\hline Not high-school graduate & 6 & 3 & 2 & 1 & 0 & 0 & 7 & 3 & 15 & 2 \\
\hline High-school graduate & 61 & 28 & 42 & 22 & 21 & 12 & 67 & 31 & 191 & 24 \\
\hline No college degree & 73 & 33 & 63 & 33 & 66 & 37 & 60 & 27 & 262 & 32 \\
\hline College degree and above & 80 & 36 & 83 & 43 & 91 & 50 & 79 & 36 & 333 & 41 \\
\hline Unavailable & 2 & 1 & 2 & 1 & 3 & 2 & 6 & 3 & 13 & 2 \\
\hline \multicolumn{11}{|c|}{ Charlson comorbidity index (pre-index period) } \\
\hline 0 & 95 & 43 & 133 & 69 & 142 & 79 & 127 & 58 & 497 & 61 \\
\hline $1-2$ & 92 & 41 & 52 & 27 & 32 & 18 & 74 & 34 & 250 & 31 \\
\hline $3+$ & 35 & 16 & 7 & 4 & 7 & 4 & 18 & 8 & 67 & 8 \\
\hline \multicolumn{11}{|l|}{ Day supply of pre-index dispensing } \\
\hline$<30$ days & 1 & 1 & 2 & 1 & 3 & 2 & 1 & 1 & 7 & 1 \\
\hline 30 days & 138 & 62 & 96 & 50 & 90 & 50 & 131 & 60 & 455 & 56 \\
\hline 60 days & 1 & 1 & 0 & 0 & 1 & 1 & 1 & 1 & 2 & $\sim 0$ \\
\hline 90 days & 83 & 37 & 94 & 49 & 87 & 48 & 86 & 39 & 350 & 43 \\
\hline \multicolumn{11}{|l|}{ Day supply of index dispensing } \\
\hline$<30$ days & 1 & 1 & 3 & 2 & 7 & 4 & 3 & 1 & 13 & 2 \\
\hline 30 days & 143 & 64 & 144 & 75 & 159 & 88 & 166 & 76 & 612 & 75 \\
\hline 60 days & 1 & 1 & 0 & 0 & 1 & 1 & 1 & 1 & 1 & $\sim 0$ \\
\hline 90 days & 78 & 35 & 45 & 23 & 15 & 8 & 50 & 23 & 188 & 23 \\
\hline Pre-index period & Mean & $\mathrm{SD}$ & Mean & $\mathrm{SD}$ & Mean & $\mathrm{SD}$ & Mean & SD & Mean & SD \\
\hline \multicolumn{11}{|l|}{ Number of: } \\
\hline Physician visits & 7 & 6 & 7 & 7 & 8 & 6 & 5 & 5 & 7 & 6 \\
\hline Emergency room visits & 1 & 2 & 1 & 3 & 1 & 4 & 1 & 2 & 1 & 3 \\
\hline Hospitalizations & 0 & 1 & 0 & $\sim 0$ & 0 & $\sim 0$ & 0 & $\sim 0$ & 0 & $\sim 0$ \\
\hline Concomitant medications & 7 & 5 & 6 & 5 & 8 & 5 & 5 & 4 & 7 & 5 \\
\hline Dispensings of study drug & 5 & 3 & 5 & 3 & 7 & 3 & 6 & 3 & 6 & 3 \\
\hline 3-digit ICD-9 diagnosis codes & 17 & 11 & 14 & 10 & 13 & 9 & 14 & 10 & 14 & 10 \\
\hline Days of use of medication & 163 & 90 & 160 & 90 & 197 & 88 & 199 & 84 & 180 & 90 \\
\hline
\end{tabular}

ICD-9, international classification of diseases, ninth revision; $S D$, standard deviation

response to the appearance changes, $21 \%$ of respondents thought they received the wrong medication (Fig. 2). This percentage was higher for lamotrigine respondents (27\%) than for lisinopril (21\%), fluoxetine (17\%), and simvastatin (19\%) respondents. Almost one-third (31\%) of respondents sought advice from their pharmacist, physician, or the Internet. Finally, $8 \%$ of respondents adjusted the use of their medications: $5 \%$ adjusted the doses, $3 \%$ used their medications less frequently; and 5\% reported stopping their prescriptions. These adjustments were more common among fluoxetine (11\%) and lamotrigine $(11 \%)$ respondents than among simvastatin (7\%) and lisinopril (5\%) respondents.

\section{Multivariable Analyses}

Multivariable modeling revealed no significant predictors of generic skepticism (Appendix 7), while patient age, pre-index number of ICD-9 codes, and days supply of index dispensing were associated with seeking advice about a pill appearance change (Table 2). Specifically, respondents age eighteen to thirty-three were more likely to seek advice about the pill appearance changes than respondents age fifty to fifty-seven $(\mathrm{OR}=1.91 ; 95 \% \mathrm{CI}, 1.02-3.59)$, as were respondents with seventeen or more ICD-9 codes on claims in the pre-index period compared to respondents with nine to sixteen ICD-9 
a Now, imagine you got a normal refill of a prescription drug you had been on for a long time. Would you like the pill ___ to be the same as usual?

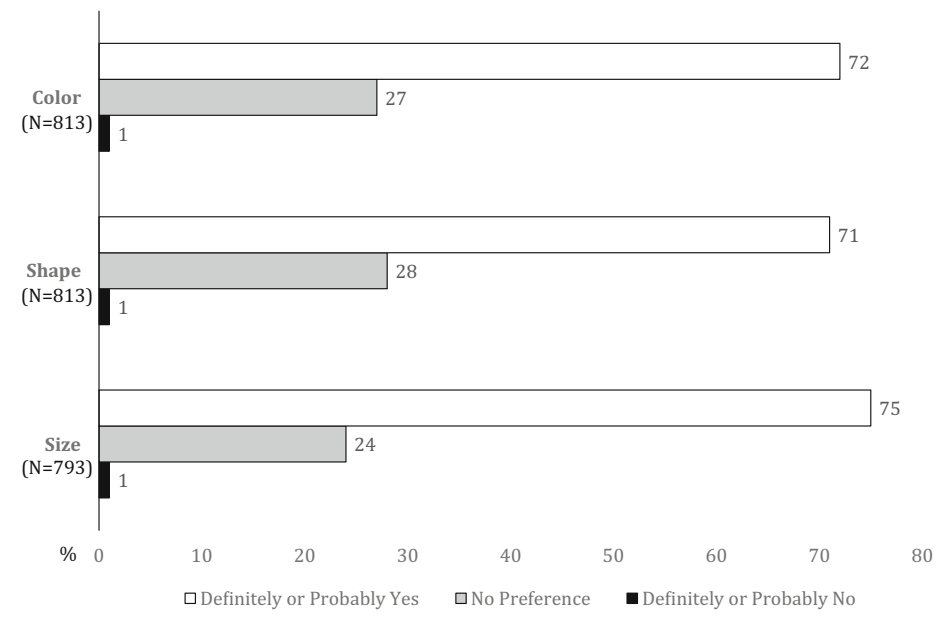

b Assume that Generic Pill costs you _ per month. It would cost the manufacturers an extra _ per month to make sure the appearance of Generic Pill remains the same every time you refill it. Would you pay __ per month for Generic Pill to make sure your pill has the same size, shape, and color at each refill?

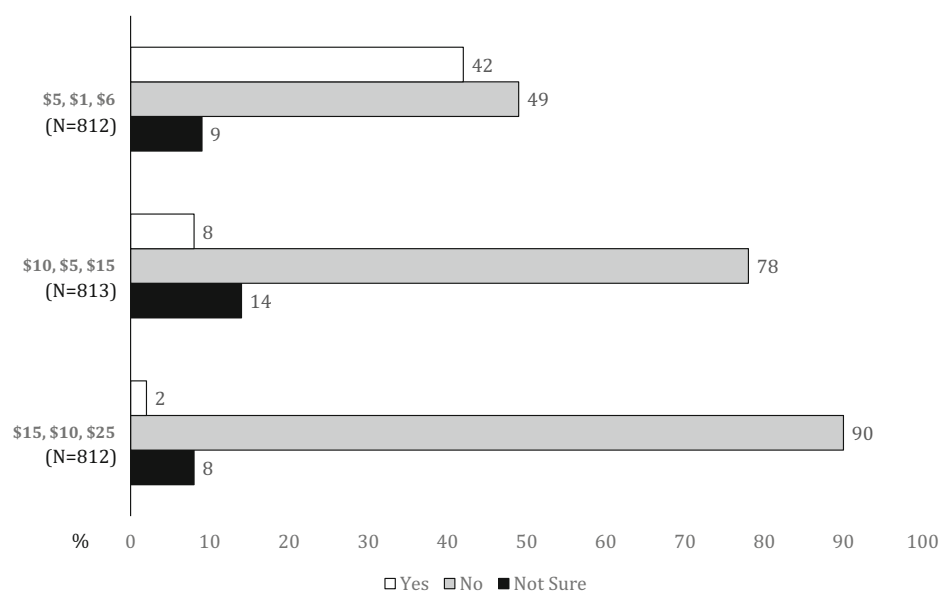

C If your pill appearance changed, would you like to be notified of the change by the pharmacy?

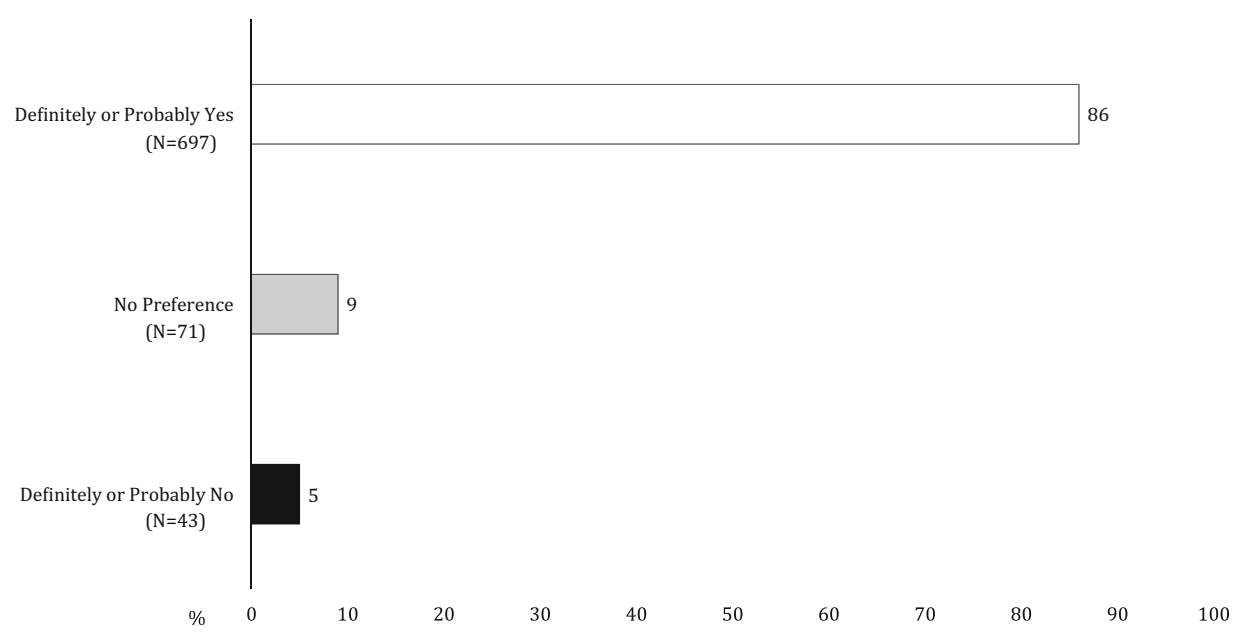

Figure 1 Pill appearance preferences. All participants. 
You may have noticed that, in the last few months, the appearance of your medication changed.

Please think back to this specific change in appearance

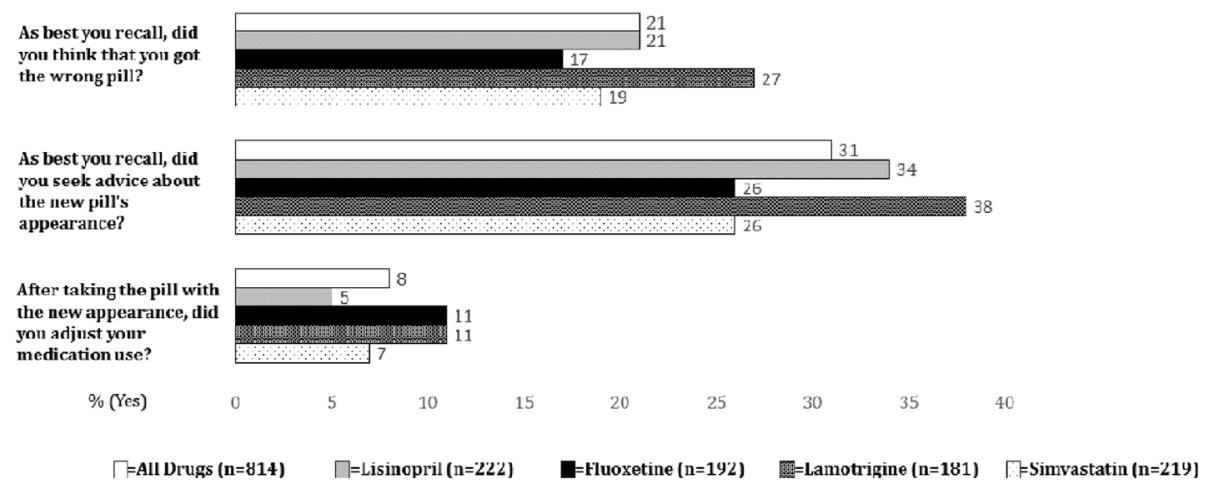

Figure 2 Responses to a recent pill appearance change. All participants stratified by study drug.

codes on claims in the pre-index period $(\mathrm{OR}=1.73 ; 95 \% \mathrm{CI}$, 1.08-2.77). By contrast, respondents receiving a sixty-day supply or more at index dispensing were less likely to seek advice than respondents receiving a less than sixty-day supply $(\mathrm{OR}=0.64 ; 95 \% \mathrm{CI}, 0.42-0.97)$.

Significant predictors of adjusting medication use (i.e., adjusting the dose, using the medication less frequently, stopping their prescription) following a pill appearance change included days supply of index dispensing, education, study drug, perception of generic drug side effects, and household income (Table 3). Respondents receiving a sixty-day supply or more at index dispensing were less likely to adjust their medication use compared to respondents receiving a less than 60 -day supply ( $\mathrm{OR}=0.20 ; 95 \% \mathrm{CI}, 0.09-0.43$ ), as were respondents with only some college education compared to respondents with a college degree $(\mathrm{OR}=0.44 ; 95 \% \mathrm{CI}, 0.20$ 0.94 ), and respondents who believed that generic drugs had the same side effects as brand-name drugs compared to respondents who did not believe that generic drugs had the same side effects as brand-name drugs $(\mathrm{OR}=0.42 ; 95 \% \mathrm{CI}$, 0.18-0.96). By contrast, respondents with a household income less than $\$ 30,000$ were more likely to change their medication use compared to respondents with a household income greater than $\$ 100,000(\mathrm{OR}=3.40 ; 95 \% \mathrm{CI}, 1.09-10.67)$.

\section{DISCUSSION}

In our survey, three-fourths of commercially insured adult patients taking one of four chronic disease medications wanted the appearance of their pills to remain the same, in part because they relied upon pill appearance to make sure they were taking the correct medication. To ensure such consistency, however, less than half (42\%) were willing to pay a $\$ 1$ premium on a $\$ 5$ co-pay. While the vast majority of patients wanted to be notified by their pharmacy about a pill appearance change, less than two-fifths (37\%) recalled their pharmacist doing so verbally or via a sticker on the pill bottle. When their pills changed appearance, over one-fifth $(21 \%)$ of patients thought they received the wrong medication and about one in ten $(8 \%)$ adjusted their medication use.

Our findings reveal broad confidence in generic drugs. Only one-fourth of patients were generic skeptics. This proportion is comparable to the proportion of generic skeptics found among a similar sample of 1450 patients with self-reported chronic conditions who had filled at least one prescription in the past three months. ${ }^{17}$ However, confidence in generic lamotrigine was lower than for generic lisinopril, fluoxetine, and simvastatin. This may be explained by the widespread but - as in the case of lamotrigine - incorrect belief that all antiepileptic drugs are so-called narrow therapeutic index drugs, for which small changes in bioavailability can lead to major clinical effects.

Our survey also raises important questions about the diversity of appearance that currently characterizes the generic drug market. The widespread reliance on pill appearance that we uncovered bolsters the hypothesis that patient confusion drove the non-persistence associated with pill appearance changes in previous investigations. ${ }^{13,14}$

Nevertheless, if generic drugs could resemble their brandname counterparts in size, color, and shape, a practical challenge to implementation could be costly, since complying with such guidance could lead to higher generic drug prices. However, most patients surveyed were unwilling to pay $\$ 1$ more to ensure uniform pill appearance despite widely preferring and relying upon such uniformity. This discrepancy warrants further research and should be weighed alongside the health benefits and health care savings possible from greater medication adherence.

That less than half of patients recalled their pharmacist notifying them about their pill appearance change highlights the greater role pharmacists could play in anticipating and addressing patient concerns. Given the impact of pill appearance changes on patient refill rates, pharmacies should implement automated pill appearance change alerts for pharmacists, require auxillary labeling highlighting pill appearance changes, and encourage pharmacists to talk with patients about such changes at the time of purchase. Such steps could be particularly helpful for lower-income patients, who were more 
Table 2 Predictors of Seeking Advice Following a Pill Appearance Change

\begin{tabular}{|c|c|c|}
\hline Independent variable & Odds ratio & $95 \% \mathrm{CI}$ \\
\hline \multicolumn{3}{|l|}{ Age group (years) on index date } \\
\hline $18-33$ & 1.91 & $1.02-3.59$ \\
\hline $34-41$ & 1.16 & $0.60-2.26$ \\
\hline $42-49$ & 1.18 & $0.69-2.00$ \\
\hline $50-57$ & Ref & - \\
\hline $58-64$ & 1.24 & $0.79-1.96$ \\
\hline 65 or over & 0.89 & $0.43-1.85$ \\
\hline \multicolumn{3}{|l|}{ Region of residence } \\
\hline Northeast & 0.53 & $0.29-0.98$ \\
\hline South & Ref & - \\
\hline Midwest & 0.82 & $0.55-1.22$ \\
\hline West & 0.55 & $0.32-0.94$ \\
\hline \multicolumn{3}{|l|}{ Sex } \\
\hline Female & Ref & - \\
\hline Male & 0.86 & $0.60-1.23$ \\
\hline \multicolumn{3}{|l|}{$\begin{array}{l}\text { Charlson comorbidity index in } \\
\text { pre-index period }\end{array}$} \\
\hline 0 & Ref & - \\
\hline $1-2$ & 1.18 & $0.79-1.78$ \\
\hline $3+$ & 1.31 & $0.67-2.54$ \\
\hline \multicolumn{3}{|l|}{ Day supply of index dispensing } \\
\hline$<60$ & Ref & - \\
\hline $60+$ & 0.64 & $0.42-0.97$ \\
\hline \multicolumn{3}{|l|}{ Day supply of pre-index dispensing } \\
\hline$<60$ & Ref & - \\
\hline $60+$ & 1.27 & $0.73-2.23$ \\
\hline \multicolumn{3}{|l|}{ Number of: } \\
\hline \multicolumn{3}{|l|}{ Physician visits } \\
\hline $0-3$ & 1.08 & $0.67-1.72$ \\
\hline $4-7$ & Ref & - \\
\hline $8+$ & 1.13 & $0.72-1.78$ \\
\hline \multicolumn{3}{|l|}{ Emergency room visits } \\
\hline 0 & Ref & - \\
\hline 1 & 1.45 & $0.91-2.33$ \\
\hline $2+$ & 1.03 & $0.57-1.83$ \\
\hline \multicolumn{3}{|l|}{ Hospitalizations } \\
\hline 0 & Ref & - \\
\hline $1+$ & 0.61 & $0.31-1.19$ \\
\hline \multicolumn{3}{|l|}{ 3-digit ICD-9 diagnosis codes } \\
\hline $0-8$ & 0.96 & $0.60-1.53$ \\
\hline $9-16$ & Ref & - \\
\hline $17+$ & 1.73 & $1.08-2.77$ \\
\hline Concomitant medications & & \\
\hline $0-3$ & 1.39 & $0.89-2.16$ \\
\hline $4-7$ & Ref & - \\
\hline $8+$ & 0.88 & $0.57-1.37$ \\
\hline Dispensings of study drug & & \\
\hline$\leq 3$ & 0.91 & $0.54-1.52$ \\
\hline$\overline{4}-7$ & Ref & - \\
\hline $8+$ & 0.80 & $0.48-1.32$ \\
\hline Days of study medication use & & \\
\hline$\leq 127$ & 0.91 & $0.52-1.58$ \\
\hline$\overline{1} 28-248$ & Ref & - \\
\hline$\geq 249$ & 1.10 & $0.70-1.73$ \\
\hline $\begin{array}{l}\text { Days between index date and survey } \\
\text { mailing }\end{array}$ & & \\
\hline$\leq 152$ & 1.13 & $0.76-1.68$ \\
\hline $153-183$ & Ref & - \\
\hline$\geq 184$ & 0.99 & $0.62-1.58$ \\
\hline Education & & \\
\hline High school or less & 1.12 & $0.70-1.80$ \\
\hline Some college/2-year degree & 0.82 & $0.53-1.26$ \\
\hline 4-year college degree & Ref & - \\
\hline Graduate school & 0.80 & $0.45-1.42$ \\
\hline Household income & & \\
\hline Less than $\$ 30,000$ & 1.62 & $0.82-3.22$ \\
\hline$\$ 30,000-\$ 49,999$ & 2.09 & $1.15-3.80$ \\
\hline$\$ 50,000-\$ 74,999$ & 1.71 & $0.99-2.96$ \\
\hline$\$ 75,000-\$ 100,000$ & 1.70 & $0.96-3.00$ \\
\hline Greater than $\$ 100,000$ & Ref & - \\
\hline Missing or unusable response & 1.58 & $0.91-2.76$ \\
\hline Study drug & & \\
\hline Lisinopril & 1.34 & $0.83-2.16$ \\
\hline Fluoxetine & 0.95 & $0.54-1.67$ \\
\hline Lamotrigine & 1.71 & $0.92-3.18$ \\
\hline
\end{tabular}

Table 2. (continued)

\begin{tabular}{lll}
\hline \hline Independent variable & Odds ratio & 95\% CI \\
\hline $\begin{array}{l}\text { Simvastatin } \\
\text { Belief that generic pills are as effective }\end{array}$ & Ref & - \\
as brand-name pills? & 0.74 & \\
Yes & Ref & $0.39-1.40$ \\
No & & - \\
$\begin{array}{l}\text { Belief that generic pills are as safe } \\
\text { as brand-name pills? }\end{array}$ & 0.53 & \\
$\begin{array}{l}\text { Yes } \\
\text { No }\end{array}$ & Ref & $0.25-1.13$ \\
$\begin{array}{l}\text { Belief that generic pills have the same } \\
\text { side effects as brand-name pills? }\end{array}$ & 1.04 & - \\
$\begin{array}{l}\text { Yes } \\
\text { No }\end{array}$ & Ref & $0.60-1.79$ \\
$\begin{array}{l}\text { Belief that generic pills are made of } \\
\text { the same active ingredients as }\end{array}$ & & - \\
brand-name pills? & & \\
Yes & & \\
No & 0.74 & $0.42-1.29$ \\
\hline
\end{tabular}

$C I$, confidence interval; ICD-9, international classification of diseases, ninth revision

likely to adjust their medication use in response to their pill appearance change. Of course, some patients switch pharmacies (e.g., Walgreens to CVS), which would require involvement from the insurer in the automated notification process.

Notably, we found that lamotrigine users were more likely than lisinopril, fluoxetine, and simvastatin users to believe they received the wrong medication, to seek advice, and to adjust their medication use in response to a pill appearance change, in addition to not recall being notified about it. A recent crossover trial suggests that these differences had little to do with therapeutic variability between generic lamotrigine products. ${ }^{20}$ Instead, it is more likely that this heightened sensitivity may reflect greater skepticism of generic antiepileptic drugs generally. ${ }^{21}$

This survey may have important implications for trade dress law that some brand-name manufacturers rely on to protect their pills' appearances and prevent similarly-looking generic counterparts. Trade dress may not be functional. As the Supreme Court has noted, " $[t]$ he functionality doctrine prevents trademark law, which seeks to promote competition by protecting a firm's reputation, from instead inhibiting legitimate competition by allowing a producer to control a useful product feature." 22 Additional case law suggests that that widespread reliance on pill appearance to take the correct medication, as reported in our survey, may constitute such a useful feature. ${ }^{23,24}$

Some limitations to our investigation should be noted. First, lower participation rates among younger patients and patients receiving a ninety-day supply of their medications at index and pre-index dispensings may limit the external validity of our findings. Second, based on data available for these analyses, we could not determine the appropriateness of changes in medication use following a change in pill appearance. While such changes may often be inappropriate, it is possible that some may be clinically warranted. Finally, like all surveys, our investigation was subject to possible recall and response biases. 
Table 3 Predictors of Changing Medication Use Following Pill Appearance Change

\begin{tabular}{|c|c|c|}
\hline Independent variable & Odds ratio & $95 \% \mathrm{CI}$ \\
\hline \multicolumn{3}{|l|}{ Age group (years) } \\
\hline $18-33$ & 1.78 & $0.64-4.95$ \\
\hline $34-41$ & 1.49 & $0.53-4.24$ \\
\hline $42-49$ & 1.05 & $0.41-2.65$ \\
\hline $50-57$ & Ref & - \\
\hline $58-64$ & 0.80 & $0.34-1.88$ \\
\hline $65+$ & 0.45 & $0.09-2.26$ \\
\hline \multicolumn{3}{|l|}{ Region of residence } \\
\hline Northeast & 0.83 & $0.31-2.22$ \\
\hline South & Ref & - \\
\hline Midwest & 0.56 & $0.27-1.18$ \\
\hline West & 0.99 & $0.41-2.39$ \\
\hline \multicolumn{3}{|l|}{ Sex } \\
\hline Female & Ref & - \\
\hline Male & 1.22 & $0.66-2.25$ \\
\hline \multicolumn{3}{|l|}{ Charlson comorbidity index } \\
\hline 0 & Ref & - \\
\hline $1-2$ & 1.17 & $0.57-2.39$ \\
\hline $3+$ & 1.21 & $0.36-4.06$ \\
\hline \multicolumn{3}{|l|}{ Days supply of index dispensing } \\
\hline$<60$ & Ref & - \\
\hline $60+$ & 0.2 & $0.09-0.43$ \\
\hline \multicolumn{3}{|c|}{ Days supply of pre-index dispensing } \\
\hline$<60$ & Ref & - \\
\hline $60+$ & 2.02 & $0.71-5.75$ \\
\hline \multicolumn{3}{|l|}{ Number of: } \\
\hline \multicolumn{3}{|l|}{ Physician visits } \\
\hline $0-3$ & 0.74 & $0.32-1.70$ \\
\hline $4-7$ & Ref & \\
\hline $8+$ & 1.2 & $0.56-2.58$ \\
\hline \multicolumn{3}{|l|}{ Emergency room visits } \\
\hline 0 & Ref & - \\
\hline 1 & 0.74 & $0.30-1.83$ \\
\hline $2+$ & 1.21 & $0.49-3.04$ \\
\hline \multicolumn{3}{|l|}{ Hospitalizations } \\
\hline 0 & Ref & - \\
\hline $1+$ & 0.8 & $0.27-2.39$ \\
\hline 3-digit ICD-9 diagnosis codes & & \\
\hline $0-8$ & 0.83 & $0.36-1.89$ \\
\hline $9-16$ & Ref & - \\
\hline $17+$ & 1.15 & $0.52-2.55$ \\
\hline Concomitant Medications & & \\
\hline $0-3$ & 1.55 & $0.70-3.43$ \\
\hline $4-7$ & Ref & - \\
\hline $8+$ & 1.37 & $0.64-2.94$ \\
\hline Dispensings of study drug & & \\
\hline$\leq 3$ & 0.74 & $0.31-1.73$ \\
\hline$\overline{4}-7$ & Ref & - \\
\hline $8+$ & 1.06 & $0.41-2.78$ \\
\hline Days of Study Medication Use & & \\
\hline$\leq 127$ & 2.49 & $0.89-7.00$ \\
\hline$\overline{1} 28-248$ & Ref & - \\
\hline$\geq 249$ & 1.01 & $0.44-2.30$ \\
\hline Days between index date and $\mathrm{s}$ & nailing & \\
\hline$\leq 152$ & 0.91 & $0.46-1.81$ \\
\hline $153-183$ & Ref & - \\
\hline$\geq 184$ & 0.52 & $0.25-1.09$ \\
\hline$\overline{\text { Education }}$ & & \\
\hline High school or less & 0.68 & $0.30-1.55$ \\
\hline Some college/2-year degree & 0.44 & $0.20-0.94$ \\
\hline 4-year college degree & Ref & - \\
\hline Graduate school & 1.31 & $0.55-3.14$ \\
\hline Household income & & \\
\hline Less than $\$ 30,000$ & 3.40 & $1.09-10.67$ \\
\hline$\$ 30,000-\$ 49,999$ & 1.72 & $0.59-5.01$ \\
\hline$\$ 50,000-\$ 74,999$ & 1.43 & $0.51-4.00$ \\
\hline$\$ 75,000-\$ 100,000$ & 2.55 & $0.91-7.14$ \\
\hline Greater than $\$ 100,000$ & Ref & - \\
\hline Missing or unusable response & 2.78 & $1.05-7.35$ \\
\hline Study drug & & \\
\hline Lisinopril & 0.31 & $0.12-0.79$ \\
\hline Fluoxetine & 1.51 & $0.61-3.71$ \\
\hline Lamotrigine & 1.12 & $0.41-3.05$ \\
\hline Simvastatin & Ref & - \\
\hline
\end{tabular}

Table 3. (continued)

\begin{tabular}{|c|c|c|}
\hline Independent variable & Odds ratio & $95 \% \mathrm{CI}$ \\
\hline \multicolumn{3}{|c|}{$\begin{array}{l}\text { Belief that generic pills are as effective } \\
\text { as brand-name pills }\end{array}$} \\
\hline Yes & 0.44 & $0.17-1.12$ \\
\hline No & Ref & - \\
\hline \multicolumn{3}{|c|}{$\begin{array}{l}\text { Belief that generic pills are as safe } \\
\text { as brand-name pills }\end{array}$} \\
\hline Yes & 2.18 & $0.63-7.52$ \\
\hline No & Ref & - \\
\hline \multicolumn{3}{|c|}{$\begin{array}{l}\text { Belief that generic pills have the same } \\
\text { side effects as brand-name pills }\end{array}$} \\
\hline Yes & 0.42 & $0.18-0.96$ \\
\hline No & Ref & - \\
\hline \multicolumn{3}{|c|}{$\begin{array}{l}\text { Belief that generic pills are made of } \\
\text { the same active ingredients as brand-name pills }\end{array}$} \\
\hline Yes & 1.26 & $0.51-3.10$ \\
\hline No & Ref & - \\
\hline
\end{tabular}

CI, confidence interval; ICD-9, international classification of diseases, ninth revision

Despite these limitations, our survey had a high response rate, revealing widespread reliance on and preference for uniform pill appearance, limited patient willingness to pay for such uniformity, limited recall of pharmacy notification of pill appearance changes, and the potential for clinically concerning responses to such changes among a minority of patients with chronic conditions. While requiring a uniform pill appearance for a drug can likely help reduce confusion and increase medication adherence, implementing such a change will likely involve practical and legal challenges. A more feasible short-term approach would be for pharmacies to adopt standardized notification and education policies for both pharmacists and patients.

Corresponding Author: Ameet Sarpatwari, J.D., Ph.D.; Program On Regulation, Therapeutics, And Law (PORTAL), Division of Pharmacoepidemiology and Pharmacoeconomics, Department of Medicine, Brigham and Women's Hospital and Harvard Medical School, Boston, MA, USA (e-mail: asarpatwari@bwh.harvard.edu).

Funding This study was supported by the FDA Office of Generic Drugs and Office of Chief Scientist (HHSF223201310232C).

\section{Compliance with Ethical Standards:}

The Partners HealthCare Institutional Review Board and the New England Independent Review Board approved this study.

Conflict of Interest: The authors declare that they do not have a conflict of interest.

Disclaimer: Views expressed in this publication do not necessarily reflect the official policies of the Department of Health and Human Services, nor does any mention of trade names, commercial practices, or organizations imply endorsement by the US Government.

Publisher's Note: Springer Nature remains neutral with regard to jurisdictional claims in published maps and institutional affiliations. 


\section{REFERENCES}

1. Generic drug access and savings in the US. Association for Accessible Medicines. https://accessiblemeds.org/resources/blog/2017-genericdrug-access-and-savings-us-report. Published 2017. Accessed October $30,2018$.

2. Sarpatwari A, Kesselheim AS. The case for reforming drug naming: should brand name trademark protections expire upon generic entry? PLoS Med. 2016;13(2):e1001955.

3. Shrank WH, Hoang T, Ettner SL, Glassman PA, Nair K, DeLapp D, et al. The implications of choice: prescribing generic or preferred pharmaceuticals improves medication adherence for chronic conditions. Arch Intern Med. 2006;166(3):332-7.

4. Gagne JJ, Choudhry NK, Kesselheim AS, Polinski JM, Hutchins D, Matlin OS, et al. Comparative effectiveness of generic and brand-name statins on patient outcomes: a cohort study. Ann Intern Med. 2014; 161(6):400-7.

5. Gagne JJ, Kesselheim AS, Choudhry NK, Polinski JM, Hutchins D, Matlin OS, et al. Comparative effectiveness of generic versus brandname antiepileptic medications. Epilepsy Behav. 2015;52(Pt A):14-8.

6. Davit BM, Nwakama PE, Buehler GJ, Conner DP, Haidar SH, Patel DT, et al. Comparing generic and innovator drugs: a review of 12 years of bioequivalence data from the United States Food and Drug Administration. Ann Pharmacother. 2009;43(10): 1583-97.

7. Gagne JJ, Avorn J, Shrank WH, Schneeweiss S. Refilling and switching of antiepileptic drugs and seizure-related events. Clinical Pharmacol Ther. 2010;88(3):347-53.

8. Hellfritzsch M, Rathe J, Stage TB, Thirstrup S, Grove EL, Damkier P, et al. Generic switching of warfarin and risk of excessive anticoagulation: a Danish nationwide cohort study. Pharmacoepidemiol Drug Saf. 2016;25(3):336-43.

9. Kesselheim AS, Bykov K, Gagne JJ, Wang SV, Choudhry NK. Switching generic antiepileptic drug manufacturer not linked to seizures: a case-crossover study. Neurology. 2016;87(17):1796-801.

10. Kesselheim AS, Misono AS, Lee JL, Stedman MR, Brookhart MA, Choudhry NK, et al. Clinical equivalence of generic and brand-name drugs used in cardiovascular disease: a systematic review and metaanalysis. JAMA. 2008;300(21):2514-26.

11. Kesselheim AS, Stedman MR, Bubrick EJ, Gagne JJ, Misono AS, Lee JL, et al. Seizure outcomes following the use of generic versus brandname antiepileptic drugs: a systematic review and meta-analysis. Drugs. 2010;70(5):605-21.
12. Ting TY, Jiang W, Lionberger $\mathbf{R}$, Wong $\mathbf{J}$, Jones JW, Kane MA, et al. Generic lamotrigine versus brand-name Lamictal bioequivalence in patients with epilepsy: a field test of the FDA bioequivalence standard. Epilepsia. 2015;56(9):1415-24.

13. Privitera MD, Welty TE, Gidal BE, Diaz FJ, Krebill R, Szaflarski JP, et al. Generic-to-generic lamotrigine switches in people with epilepsy: the randomised controlled EQUIGEN trial. Lancet Neurol. 2016;15(4):36572.

14. Kesselheim AS, Bykov K, Avorn J, Tong A, Doherty M, Choudhry NK. Burden of changes in pill appearance for patients receiving generic cardiovascular medications after myocardial infarction: cohort and nested case-control studies. Ann Intern Med. 2014;161(2):96-103.

15. Greene JA, Kesselheim AS. Why do the same drugs look different? Pills, trade dress, and public health. New Engl J Med. 2011;365(1):83-9.

16. Kesselheim AS, Misono AS, Shrank WH, Greene JA, Doherty M, Avorn J, et al. Variations in pill appearance of antiepileptic drugs and the risk of nonadherence. JAMA Intern Med. 2013;173(3):202-8.

17. Standard definitions: final dispositions of case codes and outcome rates for surveys. American Association for Public Opinion Research. http:// www.aapor.org/AAPOR_Main/media/publications/Standard-Definitions20169theditionfinal.pdf. Revised 2016. Accessed October 30, 2018.

18. Kesselheim AS, Gagne JJ, Eddings W, Franklin JM, Ross KM, Fulchino LA, et al. Prevalence and predictors of generic drug skepticism among physicians: results of a national survey. JAMA Intern Med. 2016;176(6):845-7.

19. Kesselheim AS, Gagne JJ, Franklin JM, Eddings W, Fulchino LA, Avorn J, et al. Variations in patients' perceptions and use of generic drugs: results of a national survey. J Gen Intern Med. 2016;31(6):609-14.

20. Berg M, Welty TE, Gidal BE, Diaz FJ, Krebill R, Szaflarski JP, et al. Bioequivalence between generic and branded lamotrigine in people with epilepsy: the EQUIGEN randomized clinical trial. JAMA Neurol. 2017;74(8):919-26.

21. Sarpatwari A, Lee MP, Gagne JJ, Lu Z, Dutcher SK, Jiang W, Campbell EG, Kesselheim AS. Generic versions of narrow therapeutic index drugs: a national survey of pharmacists' substitution beliefs and practices. Clin Pharmacol Ther. 2018;103(6): 1093-9.

22. Qualitex v. Jacobsen Products, 514 U.S. 159; 1995.

23. Ives Laboratories v. Darby Drug, 488 F. Supp. 394; 1980.

24. Shire US v. Barr Laboratories, 329 F.3d 348; 2003 